\title{
A IMPORTÂNCIA DA GESTÃO DE ESTOQUES PARA LOGÍSTICA DE UMA EMPRESA
}

Sidney Carvalho de Oliveira (Centro Universitário Farias Brito - FBUni) pontodigital2022@gmail.com Mauricio Johnny Loos (Centro Universitário Farias Brito - FBUni) mauricioloos@ hotmail.com

\section{Resumo}

O artigo em questão promove uma exposição do tema gestão de estoque para a logística de uma empresa, ressaltando a relevância do assunto para o avanço de uma instituição, evidenciando os aspectos relacionados e a necessidade de sua boa execução para o êxito da empresa no mercado. Para isso, apresenta uma pesquisa bibliográfica visando a coleta de artigos e livros relacionados ao tema abordado. Analisados os textos selecionados, chegou-se à conclusão que a gestão de logística é algo fundamental para o bom funcionamento e crescimento de uma empresa. Nem sempre apenas a implementação desse aspecto da logística pode melhorar ações deficitárias dentro de uma instituição comercial, sendo preciso que o gestor responsável avalie qual a melhor estratégia necessária para suprir a demanda presente na empresa.

Palavras-Chaves: Estoques, Logística, Gestão.

\section{Introdução}

Há muito tempo a gestão de estoque é vista com sua devida importância pela indústria, comércio, governo e sociedade civil. Visto isso, o processo como um todo passou, ao longo dos anos, por uma série de mudanças significativas, e que exigiram do mercado adaptações cruciais em suas estruturas, para que o sistema conquistasse uma definição uniforme em termos de aplicação dos aspectos básicos, precisos para dinamizar e potencializar a abrangência e qualidade do serviço prestado.

O controle de estoques é parte vital do composto logístico, pois este pode absorver de 25 a $40 \%$ dos custos totais, representando uma porção substancial do capital da empresa. Por esse motivo, gerenciar com cautela os estoques é de suma importância para o sucesso de qualquer organização (CHIAVENATTO, 2015). Por isso, estudos relacionados ao setor de estoques dentro de uma empresa, deve ter em seu embasamento básico uma visão bem mais profissional, e em constante aperfeiçoamento, relativa ao processo como um todo, relacionado ao armazenamento em si e a gestão envolvida na área em geral. Ainda mais, verificando na 
questão o aumento considerável de tecnologias aplicadas aos mais diferentes setores inseridos na atividade, e na capacitação do pessoal e espaços envolvidos com esse contexto logístico tão preciso para a economia e sociedade.

Desta forma, tratar dos aspectos relativos a gestão de produtos exige uma exposição ampla, e estudo profundo, sobre todos os detalhes que o envolvem, sendo coerentes sempre as evoluções ocorridas na área, e denunciando os fatos que podem ser melhorados tanto em casos específicos, quanto no setor inteiro. Isso, pois graças à uniformidade destinada ao setor nas últimas décadas, vem exigindo uma certa integração plural das empresas de armazenamento, pedindo assim, um profissionalismo cada vez maior por parte da equipe de gestão aplicada à área.

O interesse pelo desenvolvimento do tema, que culminou na pesquisa elaboração do seguinte artigo, surgiu após a leitura de estudos que evidenciaram a importância essencial do setor de estoque mesmo para áreas que, aparentemente, não parecem ser impactadas pela gestão de estoque. Em suma, a área atua dentro dessa realidade econômica, comercial e social (podendo ser relacionada também a cultura, política, etc.), como uma base estrutural, que movimenta a ação de pessoas físicas, e jurídicas, tornando os contratos socioeconômicos contemporâneos não apenas possíveis, mas amplos e plurais, tais como hoje são vistos.

Portanto, ampliar o debate acerca do tema se justifica não apenas por sua fundamental necessidade para vários âmbitos de nossa atual sociedade, como também pelas mudanças constantes ocorridas em vários setores envolvidos em sua própria realização, que são maiores e mais extensas do que inicialmente se imagina.

Para isso, o presente artigo irá buscar não só uma evidenciação do tema, mas uma atualização de suas características, analisando sua teoria aplicada e estudos de caso que possam exemplificar como essas mudanças (adequações) recorrentes podem ter melhorado o setor de estoque nos últimos anos.

De modo a nortear o desenvolvimento desse trabalho, estipulou-se como problemática a seguinte hipótese: como a gestão de estoque e armazenamento é capaz de melhorar a eficiência das empresas graças a implementação de uma boa aplicação de seus conceitos teóricos e ações práticas?

Pretendendo uma coerência com a problemática acima, evidente, o objetivo do artigo gira no entorno da conceituação da gestão de estoque, enquanto elemento logístico necessário para o crescimento e melhoria de uma empresa e/ou instituição; tendo como objetivo específico 
apresentar um panorama mais atualizado como sobre essa gestão e armazenamento vem fazendo a diferença em casos atuais e precisos sobre o tema.

Para cumprir seus objetivos, o trabalho primeiramente estabelece um referencial teórico, seguido pelos procedimentos metodológicos adotados, resultados e discussão e, finalmente, suas conclusões.

\section{Referencial teórico}

Antes de analisar os artigos que serviram de objeto para o desenvolvimento desse trabalho, é preciso conceituar o tema e evidenciar os principais aspectos relacionados a ele. Sendo assim, inicialmente cabe dizer que estoques são acumulações de matérias-primas, suprimentos, componentes, materiais em processo e produtos acabados que surgem em numerosos pontos do canal de produção e logística das empresas (BALLOU, 2011). Ainda sobre a questão, os estoques são materiais, mercadorias ou produtos que são fisicamente mantidos disponíveis pela empresa, com expectativa de ingresso no ciclo de produção, de seguir ser curso produtivo normal, ou de serem comercializados (DIAS, 2010).

O principal objetivo do estoque é ter sempre disponível o produto que o cliente precisa. Os estoques são fundamentais para a continuidade do processo de produção e vendas de qualquer empresa, porém é necessário investimento das organizações para manter estoques armazenados (GURGEL, 2012).

Os investimentos em estoque são necessários na medida em que os mesmos funcionam como um lubrificante para a produção e o atendimento das vendas. A insuficiência de estoques compromete o ritmo da produção e limita as vendas. Assim, os principais tipos de estoque encontrados em uma empresa industrial, são: matérias-primas, produtos em processo, produtos acabados, peças de manutenção e materiais auxiliares (DIAS, 2010).

As matérias-primas são os materiais que integrados compõem o produto final, ou seja, são todos os componentes agregados ao produto acabado. Vários são os fatores que afetam a quantidade de matérias-primas armazenadas, entre eles estão as características físicas e a durabilidade desses insumos. Itens perecíveis não devem ser solicitados em grandes quantidades, pois poderão se danificar antes do processo produtivo (BALLOU, 2011).

O estoque de produtos acabados é composto pelos itens já produzidos e armazenados para serem vendidos. A programação de produção é feita com o objetivo de colocar disponível um 
número suficiente de produtos acabados, para satisfazer à demanda pela previsão de vendas, sem criar estoques em excesso (DIAS, 2010).

Os produtos em processo são aqueles que já passaram por algum estágio de transformação, mas que assumirão outras características ao final da produção, e por sua vez, os materiais auxiliares e de manutenção são aqueles utilizados para manter constante a produção, sem causar a paralização e a ociosidade dos equipamentos. Ademais, ainda existem inúmeras razões para se manter estoque (BALLOU, 2011). Este mesmo autor garante que os estoques servem para uma série de finalidades, entre elas: melhorar o nível do serviço oferecido, pois os estoques quando próximos aos clientes possibilitam uma maior disponibilidade de produtos, resultando assim em uma maior satisfação na aquisição dos mesmos e consequentemente o aumento das vendas. Segundo Ballou (2011) Isto é vantajoso para clientes que precisam de disponibilidade imediata ou tempos de ressuprimento pequenos.

Ainda sobre as razões para se gerir objetos, é preciso: incentivar economias na produção, uma vez que grandes lotes de fabricação reduzem os custos unitários dos produtos, obtendo assim uma maior economia quando for mantida uma produção constante que mantenha o equilíbrio entre oferta e demanda; permitir economias de escala nas compras e no transporte. Maiores lotes de compra concedem maiores descontos tanto nas compras quanto no custo unitário do frete, permitindo uma maior economia na aquisição dos insumos (BALLOU, 2011).

Ademais, agir como proteção contra aumentos de preços. Os preços dos bens de mercado são estipulados pela relação oferta e demanda. Se a demanda por um determinado produto estiver em alta, o preço desse material aumentará. As compras podem ser antecipadas para evitar adquirir produtos quando estes estiverem em previsão de alta nos preços; proteger a empresa de incertezas na demanda e no tempo de ressuprimento.

Em geral, as previsões de vendas não são exatas. Sendo assim, não se pode afirmar com plena certeza a demanda por determinado produto. Somado a isso, o tempo de ressuprimento de estoque nem sempre é constante, pois podem ocorrer eventuais problemas na cadeia logística. Para não comprometer a disponibilidade de produto é necessário manter um nível mínimo de estoque que atenda os imprevistos (BALLOU, 2011).

E, por fim: servir como segurança contra contingências. É necessário manter estoque em ocasiões de incidentes dentro da empresa, para garantir o fornecimento dos produtos nesses períodos de contingência (BALLOU, 2011). É evidente que manter estoques traz muitos 
benefícios, porém o alto custo investido nesses ativos tornou-se um enorme problema para as empresas e um assunto a ser constantemente abordado.

No entanto, para desenvolver bem os aspectos relacionados acima, é preciso adentrar um pouco mais nos meandros da gestão de estoque, sobretudo, nos mais essenciais para a eficiência da questão. Sendo assim, cabe evidenciar o controle de estoque, uma nuance fundamental para o bom desenvolvimento dessa ação logística.

Para organizar um setor de controle de estoques, inicialmente devemos descrever seus objetivos principais, que são: determinar "o que" deve permanecer em estoque: número de itens; determinar "quando" se devem reabastecer os estoques: periodicidade; determinar "quanto" de estoque será necessário para um período predeterminado: quantidade de compra; acionar o departamento de compras para executar aquisição de estoque: solicitação de compras (GURGEL, 2012).

Além disso, consoante o autor, evidencia que é preciso: receber, armazenar e guardar os materiais estocados de acordo com as necessidades; controlar os estoques em termos de quantidade e valor e fornecer informações sobre e posição do estoque; manter inventários periódicos para avaliação das quantidades e estados dos materiais estocados; identificar e retirar do estoque os itens obsoletos e danificados (DIAS, 2010).

Ao responder essas questões, o gestor de estoque passa a ter informações suficientes para coordenar corretamente o setor de estoque, de acordo com as necessidades da empresa, buscando sempre níveis de estoque adequados.

Controle de estoque é uma espécie de função da necessidade de estipular os diversos níveis de produto, materiais que a organização precisa manter seguindo seus parâmetros econômicos. Assim, gerenciar estoques é também equilibrar a disponibilidade de produtos, ou serviço ao consumidor, por um lado, com os custos de abastecimento que, por outro lado, são necessários para um determinado grau dessa disponibilidade (BALLOU, 2011).

Sintetizando, o controle de estoque é uma função desempenhada para alcançar os objetivos determinados pela organização, através da manutenção adequada do estoque visando obter maior eficiência nos custos sem comprometer a disponibilidade dos produtos (DIAS, 2010).

O controle de estoques visa atingir o nível de produto ou serviço desejado pelo cliente, minimizando os custos relativos a esse estoque. Desta forma, é possível disponibilizar ao cliente o produto ou serviço de diversas formas, utilizando mais custos financeiros de estoque 
ou buscando minimizar esses custos atendendo ao nível de serviço solicitado (CHIAVENATTO, 2015).

O controle e dimensionamento de estoques também visa a integração entre as diversas áreas da empresa, como o setor de vendas e a produção. O setor comercial precisa de estoques em disponibilidade para realizar suas vendas com segurança, assim como a produção necessita de estoques de matéria-prima para manter constante seus processos produtivos (BALLOU, 2011).

O grande desafio da administração de estoques é conciliar de forma integrada as metas dos departamentos envolvidos, otimizando esse investimento, sem prejudicar a operacionalidade da empresa. Ainda por cima, existem certas características que são comuns a todos os problemas de controle de estoques. São elas os custos associados, os objetivos do estoque e a previsão de incertezas (CHIAVENATTO, 2015).

Sobre a questão, cabe ressaltar que existem três categorias de custos associados. São eles os custos de aquisição, custos de manutenção e os custos de falta de estoques. Os custos de aquisição geralmente incluem o preço dos produtos, os custos de processamento de pedidos pelo setor de compras e principalmente os custos de transporte quando essas taxas não fazem parte não fazem parte da compra dos produtos (GURGEL, 2012).

Os custos de manutenção compreendem aqueles derivados do armazenamento dos estoques durante determinando período. Entre eles estão o custo de espaço, que são os custos relacionados ao volume ocupado pelos estoques. Os custos de capital também estão incluídos nos custos de manutenção, pois são resultantes do custo de dinheiro imobilizado em estoque. Há também os custos dos serviços de estocagem e os custos dos riscos de estocagem (CHIAVENATTO, 2015).

Por fim, há os custos de falta de estoques. Eles ocorrem quando um pedido não pode ser atendido por falta de estoque. Nesse caso o cliente pode cancelar o pedido gerando um custo de venda perdida ou o mesmo pode esperar o atendimento, causando um custo de pedidos atrasados (BALLOU, 2011).

Entre os objetivos do estoque estão os objetivos de custo e os objetivos de nível de serviço. O objetivo de custo visa estabelecer o nível de estoque que mantenha o equilíbrio entre os custos de aquisição, manutenção e falta de estoques, minimizando assim o custo total. Os objetivos de nível de serviço buscam sempre ter produtos em disponibilidade sem que venha haver a falta de estoques (CHIAVENATTO, 2015). 
Uma das características associadas ao controle de estoque é a previsão das incertezas, que engloba a previsão de demanda e a estimativa do tempo de ressuprimento, desde a colocação do pedido até a chegada do material. Toda gestão de estoques está fundamentada na previsão de demanda de materiais, que prevê o consumo futuro em determinado período, estabelecendo quais produtos e quanto desses materiais serão comprados pelos clientes (GURGEL, 2012).

Vistos os conceitos acima, cabe uma exposição final, de modo a complementar essa nuance teórica, necessária ao entendimento de tópicos posteriores, mais precisamente aos termos: ponto de pedido; tempo de reposição e estoque de segurança.

As empresas precisam de métodos de controle de estoque que indiquem as necessidades de manutenção e suprimento de materiais, mantendo níveis adequados, para que os estoques não faltem e nem excedam demasiadamente a demanda dos clientes e os padrões trabalhados pela empresa. Para um controle efetivo e eficaz, é indispensável o uso de técnicas executadas periodicamente e permanentemente para acompanhar e manter níveis de estoque satisfatórios, que não comprometam a produção e reduzam os custos totais gastos com esses ativos imobilizados (DIAS, 2010).

Gurgel (2012) são os insumos encontrados no estoque que asseguram o processo de produção para que não ocorram problemas de continuidade, enquanto é esperada a chegada do lote de compra feito anteriormente.

Para que se possa encontrar o estoque mínimo necessário ao funcionamento contínuo das empresas e ao atendimento da demanda dos clientes é fundamental determinar o tempo de reposição dos estoques. Tempo de reposição é o tempo gasto desde a verificação de que o estoque precisa ser reposto até a chegada efetiva do material no almoxarifado da empresa.

De acordo com Dias (2010), esse tempo pode ser dividido em três partes: emissão do pedido é o tempo que leva desde a emissão do pedido de compra até a ordem de compra chegar ao fornecedor; preparação do pedido é o tempo que leva desde o fornecedor fabricar os produtos, separar os produtos, emitir faturamento até deixá-los em condições de serem transportados; transporte é o tempo que leva da saída do fornecedor até o recebimento pela empresa dos materiais encomendados.

O tempo de reposição é de grande importância, pois o cálculo do prazo de ressuprimento dos estoques pode alterar toda sua estrutura. É necessário que sejam avaliadas todas as características e prazos dos fornecedores, de forma a determinar o tempo de reposição o mais realista possível para que suas variações sejam mínimas. É preciso também verificar os 
materiais individualmente, pois cada um possui seu tempo de reposição, e este tempo é determinado pelo ponto de pedido, indicador que aponta a quantidade mínima em que um produto deve se encontrar para que seja resposto novamente (CHIAVENATO, 2015).

Segundo Ballou (2011) a finalidade do ponto de pedido ou ponto de reposição é dar início ao processo de ressuprimento com antecipação suficiente para não ocorrer falta de material. Quando um produto chega ao seu ponto de pedido a empresa precisa fazer seu ressuprimento, emitindo um pedido de compra.

Quando o estoque chega ao ponto de pedido (PP) é o momento de realizar um novo pedido, iniciando o tempo de reposição, período que compreende a emissão do pedido (1), a preparação do pedido (2) e o transporte dos materiais (3), até a chegada do estoque na empresa. É fundamental emitir um novo pedido no ponto de pedido, para que decorrido o tempo de reposição, o novo lote de compra chegue a empresa e mantenha o estoque mínimo ou estoque de segurança (EM) constante (BALLOU, 2011).

Por fim, os conceitos teóricos acima evidenciam que a gestão de estoque é uma rede ampla, complexa, e que exige da instituição, e de seus funcionários, uma coerência direcionada e que permita esse setor de estoque funcionar como um todo para proporcionar a funcionalidade dessas ações necessárias.

\section{Procedimentos metodológicos}

Este trabalho adotou como procedimento metodológico inicial uma pesquisa bibliográfica, visando a coleta de artigos relacionados ao tema abordado, no caso a Gestão de Estoques, buscando essas referências em uma base de dados bastante conhecida por acomodar uma infinidade de artigos acadêmicos não apenas de qualidade, mas atuais e capazes de agregar à qualquer pesquisa pretendida, no caso a SciELO (Scientific Eletronic Library Online).

Colhidos os artigos (inseridos em publicações e livros relacionados ao tema), após uma busca precisa, utilizando como descritores os termos adicionados no título desse artigo (gestão; estoques), serão adicionados nesse trabalho não apenas textos que resguardem essa temática, mas que tenham sido desenvolvidos nos últimos dez anos, de modo a propor uma atualização do conteúdo desse artigo e do tema relacionado.

Acerca desse tipo de pesquisa, cabe dizer que o levantamento bibliográfico é normalmente feito a partir da análise de fontes secundárias que abordam, de diferentes maneiras, o tema escolhido para estudo. As fontes podem ser livros, artigos, documentos monográficos, 
periódicos (jornais, revistas, etc.), textos disponíveis em sites confiáveis, entre outros locais que apresentam um conteúdo documentado (MARCONI; LAKATOS, 2014).

Após a seleção do material, este deverá ser lido, analisado e interpretado. Durante o processo da pesquisa bibliográfica é importante que o pesquisador faça anotações e fichamentos sobre os conteúdos que forem mais importantes, e que eventualmente serão usados como fundamentação teórica em seu trabalho (MARCONI; LAKATOS, 2014).

Realizada a pesquisa bibliográfica, a análise dos textos e desenvolvimento do trabalho se deu por meio de um teor qualitativo, visando não apenas uma eficiência quanto ao trato com a temática proposta, mas também a elaboração de um texto com qualidade, capaz de demonstrar a situação da questão no atual momento do setor.

A Pesquisa Qualitativa é definida como um tipo de investigação voltada para os aspectos qualitativos de uma determinada questão. Considera a parte subjetiva do problema. Isto significa que ela é capaz de identificar e analisar dados que não podem ser mensurados numericamente. Pode-se citar como exemplo a observação e análise de sentimentos, percepções, intenções e comportamentos. Os resultados deste tipo de pesquisa não são apresentados através de recursos estatísticos. Nesta pesquisa, os dados obtidos não são, portanto, tabulados para obtenção de resultado (GIL, 2013).

\section{Discussão de resultados}

Observados os artigos selecionados para compor essa pesquisa, é possível afirmar que as empresas na atualidade, tem buscado otimizar cada vez mais esse setor fundamental de sua logística, sobretudo, por entender que não avançar dessa área pode ser crucial para perder espaço no mercado, em especial, para outras que tenham uma atenção maior a esse contexto abordado.

Os artigos selecionados para a análise do tema, juntamente com o referencial teórico, abordaram a questão em diferentes campos de atuação, ressaltando com isso a importância desse setor como um todo no ambiente comercial/econômico presente no caso. Por exemplo, tome-se o contexto da pesquisa de Kunigami e Osório (2009), que abordaram o tema dentro de uma montadora automobilística. Os autores, para analisar a questão, propuseram uma comparação entre gestões, sendo uma menos atenta ao setor, e outra mais precisa quanto aos investimentos e propostas de melhoria. 
Nesse caso, se propôs a redução do estoque, de modo a diminuir os custos e aumentar a receita disponível para o investimento em outras áreas, algumas, até responsáveis por aumentar o volume de distribuição, contribuindo para essa diminuição no número de peças estocadas. A proposta ousada, apesar de incomum no geral, proporcionou à empresa uma redução de aproximadamente $42 \%$ que pode ser considerado como um valor que não foi gasto para a reposição plena dos estoques. Isso se levar em conta que seria necessário um maior espaço físico para o armazenamento de todos esses itens para a política anterior (KUNIGAMI; OSÓRIO, 2009). Sendo o mais antigo dos artigos selecionados, ele evidencia que propostas inovadoras e responsáveis por melhorar a gestão, e diminuir os custos com qualidade, já ocupam quase uma década nesse mercado, e só vem aumentando com o passar do tempo.

Já Rocha e Fontes (2017) detém sua análise sobre uma indústria têxtil no interior da Paraíba, cidade longe dos grandes polos econômicos, e que apresenta aspectos e necessidades diferentes desses cenários mais complexos e diferentes. Nessa pesquisa de campo, constatouse que a falta de uma gestão de estoque moderna, que faça uso de tecnologias como meio de facilitador do processo logístico, pode trazer uma série de prejuízos à empresa, impedindo que ela cresça de forma eficiente e rápida.

Conforme ressaltaram os autores, essa falta de gestão do estoque os obriga a fazer um número muito grande de compras emergenciais e não consegue ter definida qual a quantidade exata a ser comprada e qual programação de compras ideal para reposição do mesmo, conseguindo, assim evitar a falta de itens ou até mesmo zerá-las, ocasionando uma série de contratempos e falta de lucro em algumas negociações.

A pesquisa de Rocha e Fontes (2017), além de demonstrar que ainda existem empresas que não enxergam a fundamental importância da gestão de estoque, sobretudo em localidades mais distantes dos grandes centros urbanos e comerciais, ainda denuncia a negligência em relação a tecnologia e preparo de pessoal, fatores essenciais para que o tema haja como um aliado no crescimento e bom funcionamento de uma empresa.

Silva e Rabelo (2017) transitam entre os aspectos mais evidentes do tema, de maneira atual e engajada, ressaltando a relevância essencial da tecnologia para a questão. Em suma, a pesquisa deles apresenta que com o avanço da tecnologia ficou mais fácil o monitoramento do controle estoques porque o próprio computador avisa quando é necessária a compra ou fabricação de materiais facilitando o trabalho dos gestores. As empresas que utilizam métodos 
de controle têm maior chance de obter sucesso por acompanhar com cautela o seu processo de estocagem.

Embora seja uma relação óbvia, após conhecer os aspectos mais precisos sobre o tema, a utilização da tecnologia nesse contexto exige o conhecimento dos sistemas disponíveis, e a análise se aquele recurso tecnológico é o mais adequado para a ocasião, pois, nem sempre a presença de uma gestão mais automatizada, irá proporcionar melhores resultados de forma orgânica. É preciso estabelecer uma análise das nuances presentes, de modo a dar maior eficiência e coerência a aplicação dessa abordagem moderna.

Wernke, Lemberck e Nascimento (2011), direcionam o seu estudo à uma indústria têxtil de médio porte, localizando em um tipo específico de comércio e tamanho de abrangência, como a gestão de negócios pode atuar para melhorar os resultados comerciais (e econômicos), de modo a proporcionar um crescimento mais rápido.

Todavia, a pesquisa destaca que, mesmo dentro de uma proposta de gestão bem-intencionada e em crescimento, existem problemas que devem ser sanados, de modo a dar maior qualidade a esse tipo de gestão. Dentre esses aspectos, o cuidado com a implementação de tecnologia e formação do pessoal, surgem como nuances que podem ajudar, ou atrapalhar, de acordo com os investimentos e preparação oferecidas.

Raimundi e Benetti (2017) também investiram na pesquisa de campo para vislumbrar como a gestão de estoque é encarada, e aplicada, em empresas inseridas em um grande pólo industrial (caso diferente de alguns dos estudos anteriores). Em um ambiente mais competitivo, como é Chapecó, constatou que as empresas consideram como uma ferramenta fundamental para o bom andamento das organizações, pois além de agregar valor ao capital quando analisado como riqueza da entidade, é ali que o resultado se define, levando em consideração que toda produção passa pelo estoque diretamente, além de influenciar diretamente na competitividade.

Conforme os autores em questão, o estoque é um dos agentes que mais tem influência dentro de uma organização, interage com os demais departamentos, tais como compras, vendas, produção e outras, por isso tem uma parcela de importância muito grande para o bom funcionamento da empresa (RAIMUNDI; BENETTI, 2017).

De acordo com sua pesquisa, as empresas comerciais contam com grandes números de estoque devido as exigências da demanda, logo, faz se necessário uma gestão eficaz nos controles desses estoques para evitar possíveis faltas, perdas e obsolescências. Diante disso, dispõe se de inúmeras ferramentas e softwares altamente desenvolvidos para atender a essas. 
Cardoso e Pereira (2014) estudaram como a gestão de estoque pode impactar, diretamente, no aumento de vendas, sobretudo, de alguns produtos mais específicos. Após sua observação, os resultados possibilitaram, com base nas variáveis receitas de vendas, na margem de contribuição, na quantidade vendida e no giro do estoque, identificar alguns grupos de produtos que mais se destacam nas vendas, sendo representados por papel sulfite, canetas esferográficas e cadernos, totalizando $90 \%$ do faturamento dessa organização.

Os procedimentos necessários para a melhoria da gestão de estoques e compras da empresa analisada, passam primeiramente pela detecção de seus pontos fortes e fracos no controle de estoque, pela compreensão dos sócios-proprietários de que alguns fatores chaves precisam ser definidos, para que o sistema de controle nas compras e vendas seja eficiente de modo que a empresa saiba identificar suas necessidades de estoque mínimo através da previsão de sua demanda (CARDOSO e PEREIRA, 2014).

Por fim, Rossler e Hofmeister (2016) desenvolveram um estudo bastante amplo e direcionado a gestão de estoque interno de uma empresa, buscando verificar um aumento nos lucros, e contenção de despesas, graças a melhoria nessa área da logística em uma instituição de médio/grande porte.

Como resultado, eles constataram que os sistemas podem impactar como metodologia de redução de valor, posto que ao basear-se nestes arquivos e informações, elaboram-se relatórios regulares acerca das quantidades e valores contidos em estoque para diferentes itens em armazenagem, desta forma aferem-se dados significativos de auxílio à gerência, particularmente no que se refere ao monitoramento do desempenho e do controle efetivo na gestão do estoque, permitindo que as decisões do setor sejam fundamentadas na previsão da demanda futura aliada ao menor custo.

De acordo com os artigos acima, a implementação de um sistema de gestão de estoque é essencial para o funcionamento pleno de uma empresa. Tanto que, nos cenários onde essa etapa da logística foi aplicada com eficiência, inclusive fazendo uso da tecnologia, elas não apenas cresceram, mas deixaram de ter gastos devido à falta de organização.

Do mesmo modo, em cenários onde a gestão ainda não se fez presente, ou não atende aos seus objetivos em plenitude, a empresa acaba sendo prejudicada de várias maneiras, e acaba retraindo ou perdendo espaço para concorrentes mais atentos a essa questão fundamental. 


\section{Conclusões}

Vistos os aspectos teóricos desta pesquisa, e os artigos selecionados para análise do tema, chegou-se à conclusão que a gestão de logística é algo fundamental para o bom funcionamento, e crescimento, de uma empresa. Todavia, nem sempre apenas a implementação desse aspecto da logística pode melhorar ações deficitárias dentro de uma instituição comercial. É preciso que o gestor responsável avalie qual a melhor estratégia necessária para suprir a demanda presente na empresa.

O uso de tecnologia também surge como uma nuance relevante (essencial) para a eficiência desse tipo de gestão, todavia, é preciso todo um cuidado e planejamento para que esse tipo de recurso atue como aliado, e não inimigo, da empresa. Isto pois, adotar um sistema não adequado à realidade da empresa pode mais atrapalhar, e gerar gastos desnecessários, do que melhorar a gestão de estoque e crescimento da instituição.

Sendo assim, cabe enxergar essa nuance como algo fundamental e em constante evolução, principalmente, em mercados emergentes como o brasileiro, que está em constante mudança, principalmente, econômica.

\section{REFERÊNCIAS}

BALLOU, Ronald H. Logística empresarial: transportes, administração de materiais e distribuição física. São Paulo: Atlas, 2011.

CARDOSO, Wellington José; PEREIRA, Eliphas Levi. A importância da gestão de estoques nas estratégias competitivas da empresa Pinheiro Produtos de Papelaria LTDA. Revista Perquirere, 11(2): 108-129, dez. 2014

CHIAVENATO, Idalberto. Administração Produção: uma abordagem introdutória. Rio de Janeiro. Elsevier, 2015.

DIAS, Marco Aurélio P. Administração de Materiais: uma abordagem logística. $4^{\text {a }}$ edição. São Paulo: Atlas, 2010.

GIL, A. C. Como elaborar projetos de pesquisa. 9. ed. São Paulo: Atlas, 2013.

GURGEL, Floriano do Amaral; FRANCISCHINI, Paulino G. Administração de Materiais e do Patrimônio. São Paulo: Thomson - Pioneira, 2012.

KUNIGAMI, F. J; OSÓRIO, W. R. Gestão no controle de estoque: estudo de caso em montadora automobilística. 2009. Artigo, Revista Gestão Industrial. Universidade Tecnológica Federal do Paraná UTFPR Campus Ponta Grossa - Paraná. 
MARCONI, M. A. de; LAKATOS, E. M. Técnicas de pesquisa: Planejamento e execução de pesquisas. 7. ed. São Paulo: Atlas, 2014.

RAIMUNDI, Odineia; BENETTI, Juliana Eliza. As Contribuições da Gestão no Controle de Estoques em Duas Empresas de Construção Localizadas em Chapecó - SC. Revista Tecnológica. V.6, n 1, 2017.

ROCHA, Fernanda Ingridy Lima da; FONTES, Descartes Almeira. A Importância da Gestão de Controle de Estoques em uma Empresa Textil: Um Estudo de Caso na Cidade de São Bento - PB. Revista FAFIC, 6 $6^{\mathrm{a}}$ ed. Vol. 7, n 7, 2017.

ROSSLER, Edson Mauri; HOFMEISTER, Luiz Fernando. Gestão de Estoques: Um Estudo de Caso na Empresa PEPPA. Revista de Administração Dom Alberto. v. 3, n. 2, dez. 2016

SILVA, Mislene Gontijo; RABELO, Maria Helena Silva. Importância do Controle de Estoques para as Empresas. Revista Acadêmica Conecta FASF. Vol. 2 (238-254), 2017.

WERNKE, Rodney; LEMBECK, Marluce; NASCIMENTO, Fábio de Araújo. Gestão financeira de estoques: estudo de caso em indústria têxtil de médio porte. Revista brasileira de contabilidade. Rio de Janeiro, v.40, $\mathrm{n}^{\circ}$ 190, p.65-75 p., 2011. 